\title{
Respiratory and muscular effects of a physiotherapy protocol carried out during hemodialysis in individuals with Chronic Renal Failure: preliminary results
}

\author{
Mayara Simões $^{1}$ (D), Michele Lima Gregório ${ }^{2}$ (D), Moacir Fernandes de Godoy ${ }^{2,3}$ (D), Marilita Falângola Accioly ${ }^{1}$

\begin{abstract}
${ }^{1}$ Universidade Federal do Triangulo Mineiro, Departamento de Fisioterapia, Programa de Pós-graduação em Fisioterapia, Uberaba, MG, Brasil; ${ }^{2}$ Faculdade de Medicina de São José do Rio Preto, Núcleo TransdisciSão José do Rio Preto, Departamento de Cardiologia e Cirurgia Vascular, São José do Rio Preto, SP, Brasil.
\end{abstract} \\ plinar para o Estudo do Caos e da Complexidade, São José do Rio Preto, SP, Brasil, ${ }^{3}$ Faculdade de Medicina de
}

\begin{abstract}
Aim: To analyze whether the proposed physiotherapy protocol during hemodialysis (HD) increases knee extensor muscle strength, palmar grip strength, respiratory muscle strength, lung function, and functional capacity of individuals with Chronic Renal Insufficiency (CRI) on HD. Methods: A preliminary results study, in which physical therapy intervention was performed in 11 subjects $(49.2 \pm 8.6$ years) with CRI on HD treatment. Initially, Heart Rate Variability (HRV) was collected, with the individual at rest, for 15 minutes, and later, HRV linear and non-linear analyses were performed using HRV Kubios Premium Software. The protocol was performed in the first two hours of the HD session, three times a week for eight weeks, consisting of respiratory exercises, aerobic exercises, and electrical stimulation associated with progressive resistive exercises. The variables evaluated were respiratory muscle strength, knee extensor muscle strength, palmar grip strength, lung function, and functional capacity. Student's t-tests for paired samples and Wilcoxon's tests for non-parametric samples were used considering a significance level of 5\%. Results: There was a significant increase in expiratory muscle strength $(p=0,012$; Cohen's $d=0,59)$, knee extensor muscle strength ( $p=0,025$; Cohen's $d=0,77)$, palmar grip strength $(P=0,001$; Cohen's $d=0,52)$ and functional capacity $(\mathrm{P}=0,009$; Cohen's $\mathrm{d}=0,83)$. Conclusion: The proposed protocol is effective in increasing knee extensor muscle strength, palmar grip strength, expiratory muscle strength, and functional capacity of individuals with CRI on HD.
\end{abstract}

Keywords: exercise; renal dialysis; renal insufficiency, chronic.

\section{Introduction}

Chronic Kidney Disease (CKD) consists of lesions of the kidney and progressive and irreversible loss of kidney function. In a more advanced stage, it is called Chronic Renal Failure (CRF)1. $\mathrm{CRF}$ can be considered a syndrome with diverse effects on the cardiovascular, nervous, respiratory, musculoskeletal, immune, and endocrine systems2.

CRF has direct effects on the respiratory system, characterized by alterations, such as airflow limitation, obstructive disorders, reduced pulmonary diffusion capacity, decreased endurance, and respiratory muscle strength ${ }^{3}$. These respiratory alterations are related to muscle fibrous atrophy type I and type II, alterations in oxygen transport, extraction and consumption, vitamin D deficiency, increased protein catabolism, and energy metabolism dysfunction ${ }^{4,5}$. According to some studies ${ }^{6,7}$, respiratory muscle strength and lung function of individuals with CRF on HD are lower than in the general population. In addition, pulmonary dysfunction is considered an independent predictor of increased mortality in patients with $\mathrm{CKD}^{8}$.

Another physiological system very affected in this population is the musculoskeletal system. The uremic muscle loss of these individuals is complex and progressive, similar to that of sarcopenia ${ }^{9}$. Muscle weakness is a common symptom and is due to factors such as hormonal imbalance, malnutrition, chronic anemia, lifestyle changes, loss of muscle mass, and weakness due to atrophy of muscle fibers ${ }^{10}$. This devastating complication contributes to a sedentary lifestyle, worsens the quality of life, and increases the occurrence of cardiovascular complications, morbidity, and mortality9.

Cardiovascular complications are prevalent among individuals with CRF on dialysis ${ }^{11}$, representing the main cause of morbidity and mortality in this population ${ }^{12}$. The occurrence of cardiac arrhythmia in patients with CRF is associated with the autonomic dysfunction evidenced by reduced heart rate variability $(\mathrm{HRV})^{13}$. 
HRV analysis of this population shows persistent sympathetic overactivity ${ }^{14}$, and reduction of the parasympathetic action in the heart ${ }^{15}$. This reduced HRV is caused by several events, including microalbuminuria and macroalbuminuria, decreased glomerular filtration rate, and end-stage renal disease ${ }^{16}$. Other factors also influence low autonomic cardiac modulation, namely advanced age, diabetes mellitus, sedentary lifestyle, and arterial hypertension ${ }^{17}$.

These individuals show a reduced functional capacity when compared to health ones ${ }^{18}$. The implementation of a rehabilitation program for these individuals is effective, safe and viable, independent of the stage of illness ${ }^{19}$, due to expected benefits, such as improved quality of life, preservation of autonomy, reduction of cardiovascular complications, morbidity and mortality, as well as a better prognosis for this population ${ }^{20,21}$.

The benefits promoted by physical exercises to this group is widely described. However, the number of studies using resistance training and neuromuscular electrical stimulation is reduced. The neuromuscular electrical stimulation alone improves the physical condition of individuals with CRF on $\mathrm{HD}$ and has a positive effect on the pulmonary function and working capacity, which improves their physical performance ${ }^{22}$.

Thus, the purpose of this study was to analyze whether the physiotherapy protocol proposed during HD increases knee extensor muscle strength, palmar grip strength, respiratory muscle strength, lung function, and functional capacity of individuals with CRF on HD.

\section{Methods}

\section{Study design}

These are preliminary data from a before and after quasi-experimental study. Eleven participants $(49,2 \pm 8,6$ years old) acted as their quantitative respective control. The outcomes were acquired before and after the 8-week intervention period (Figure 1).

This study was approved by the Ethics and Research Committee of the Federal University of Triângulo Mineiro (number: 1.941.876). All participants signed an Informed Consent Document. This study protocol was prospectively registered in the Brazilian Registry of Clinical Trials (RBR-653hw7).

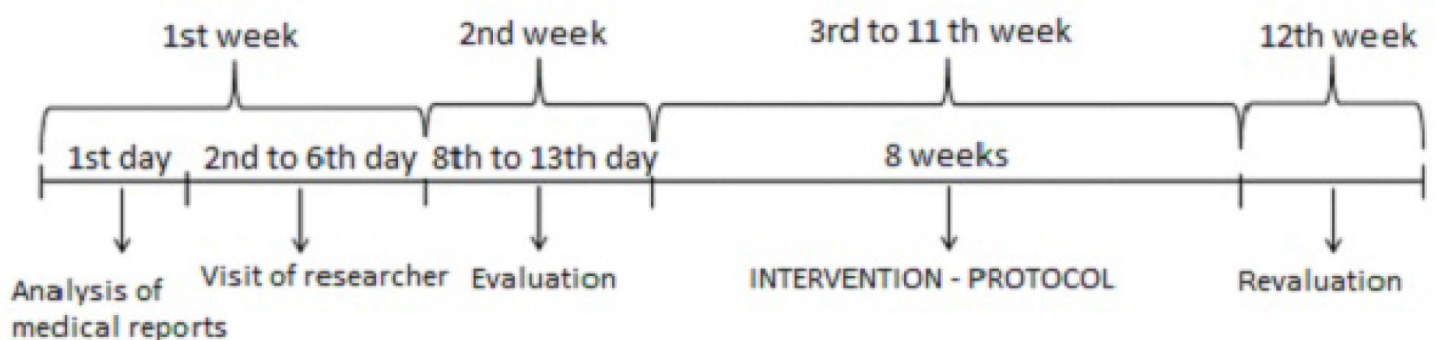

Figure 1 - Study Design

\section{Participants}

Participants were recruited through the review of medical records and during a consultation with the HD department in two hospitals in the city of Uberaba-MG.

Initially, all individuals who had a clinical diagnosis of stage 5 $\mathrm{CKD}^{1}$ and had been on HD for at least three months were selected. The following individuals were not included in the study: smokers; alcoholics; individuals with a history of acute myocardial infarction or heart failure; individuals using a cardiac pacemaker; individuals with severe visual and/or intellectual disability; and individuals with amputations or incapacitating disorders of the lower limbs.

Exclusion criteria were: persistent hemodynamic instability at rest, characterized by systolic blood pressure higher than 180 or lower than $90 \mathrm{mmHg}$, diastolic blood pressure higher than 100 or lower than $50 \mathrm{mmHg}$, and/or heart rate (HR) higher than 120 or lower than $60 \mathrm{bpm}$; muscle disorders; hospital admissions during the research; changes of HD centers; and adherence to protocol of less than $70 \%$.

In addition, the sample was characterized according to the indices for HRV using a linear analysis (time and frequency domains) and a non-linear analysis using the Chaos Theory (Table 1), to identify the patient's cardiovascular prognosis, which is a morbidity and mortality factor ${ }^{12}$. For the HRV analysis, instantaneous RR intervals (RRi) were captured using a Polar brand heart rate monitor, model RS800CX (Polar, Kempele, Finland), consisting of a transmitting chest strap placed on the distal third of the sternum, from which the data were transmitted to a pulse sensor. This methodology was validated and yielded accurate and reliable results ${ }^{23}$.

TABLE 1 - Characterization of Heart Rate Variability in participants with Chronic Renal Failure on hemodialysis $(\mathrm{n}=11)$.

\begin{tabular}{cc}
\hline HRV & Value \\
\hline Linear Analysis - Time Domain & \\
Mean RR (ms) & $777.28(153.43)$ \\
RMSSD (ms) & $14.49(13.14)$ \\
PNN50 (\%) & $3.22(8.06)$ \\
SDNN index (ms) & $21.04(12.89)$
\end{tabular}




\begin{tabular}{cc}
\hline HRV & Value \\
\hline RR tri index & $5.69(3.19)$ \\
TINN $(\mathrm{ms})$ & $119.54(60.71)$ \\
Linear Analysis - Frequency Domain & \\
VLF $\left(\mathrm{ms}^{2}\right)$ & $298.62(240.38)$ \\
LF $\left(\mathrm{ms}^{2}\right)$ & $184.11(283.02)$ \\
HF $\left(\mathrm{ms}^{2}\right)$ & $50.90(96.86)$ \\
BF/AF (ms $\left.{ }^{2}\right)$ & $9.41(10.69)$ \\
Non-Linear Analysis & \\
SD1 $\left(\mathrm{ms}^{2}\right)$ & $10.25(9.29)$ \\
SD2 (ms) & $30.38(16.58)$ \\
ApEn & $1.16(0.24)$ \\
SampleEn & $1.17(0.33)$ \\
ShanEn & $3.86(0.60)$ \\
\hline
\end{tabular}

Mean RR: mean RR intervals; RMSSD: root mean square successive difference between adjacent normal RR intervals; pNN50: number of pairs of adjacent $\mathrm{NN}$ intervals differing by more than $50 \mathrm{~ms}$ in the entire recording; SDNN index: standard deviation of mean NN intervals; RR tri index: triangular RR index; TINN: triangular interpolation of the NN interval histogram; VLF: very low frequency; LF: low frequency; HF: high frequency; LF/HF: ratio of low frequency to high frequency; SD1: short-term beat-to-beat variability; SD2: long-term beat-to-beat variability; ApEn: Approximate Entropy; SampleEn: Sample Entropy; ShanEn: Shannon's entropy. Data expressed as mean (standard deviation).

The collection was performed before the HD session. The participants were asked to sit quietly and not fall asleep, to perform minimal movements, and to breathe spontaneously for 15 minutes. Ten minutes of silence was allowed to ensure that the participants were sufficiently relaxed before the RRi were captured.

Beat-to-beat HR was recorded, scanned at $1000 \mathrm{~Hz}$, and imported into Polar Precision Performance SW (version 4.01.029; Polar). Next, the data were filtered using the same software. This program allows identification of occasional ectopic beats (abnormal heart rhythm with extrasystoles and consecutive compensatory pauses) and replaces these with interpolated adjacent RRi values.

For the analysis of the HRV indices, 1000 RRi obtained from the most stable section of the tracing were used. The intervals were digitally filtered to eliminate artifacts according to the protocol T-RR filter ${ }^{24}$. Only time series with less than $5 \%$ of artifacts were included for analysis.

The HRV analysis was performed using Kubios HRV Premium Analysis Software (Biosignal Analysis and Medical Image Group, University of Eastern Finland, Kuopio, Finland) ${ }^{25}$, with linear and non-linear analyses.

\section{Linear Analysis of $H R V$}

The time-domain (TD) HRV analysis included the mean RRi (mean RR), the standard deviation of the mean normal RRi (SDNN), the percentage of adjacent RRi that differ due to duration greater than 50 milliseconds (ms) (pNN50), and the quadratic root of mean square differences between the usual adjacent RRi (RMSSD) in ms.

Frequency-domain (FD) measurements, calculated in milliseconds squared $\left(\mathrm{ms}^{2}\right)$ and using the fast Fourier transform, included very low frequency (VLF) spectral components $(<$ $0.04 \mathrm{~Hz})$, low frequency (LF) band $(0.04-0.15 \mathrm{~Hz})$, high frequency (HF) spectral component $(0.15$ to $0.40 \mathrm{~Hz})$, as well as the ratio between these components (LF/HF).

Geometric methods, such as the RR tri index and the triangular interpolation of the NN interval (TINN) histogram, were also used. These indices were analyzed in absolute units (ms).

\section{Non-Linear Analysis of HRV}

For the non-linear HRV analysis, the following Poincaré indexes were included: SD1, SD2, Approximate Entropy (ApEn), Sample Entropy (SampEn), and Shannon Entropy (ShanEn).

\section{Intervention}

Evaluations were performed one hour before the beginning of the HD session. The participants were instructed to wear appropriate clothing (light clothes); to use comfortable shoes (sneakers); to have a balanced diet for at least two hours before the test; not to consume stimulating beverages such as tea and coffee; and not to perform strenuous physical activity.

\section{Experimental protocol}

The protocol was performed three times a week for eight weeks, totaling 24 sessions, with an average duration of 60 minutes each.

At first, the participants' vital signs were measured during the intervention. The proposed protocol consisted of:

Breathing exercises with a flow incentive spirometer and inspiratory muscle trainer. The load of the inspiratory muscle trainer was increased by $10 \%$, every two weeks starting with $10 \%$ of the maximum inspiratory pressure (MIP), to reach $40 \%$ of the MIP value in the last two weeks of the protocol. Three sets of 10 repetitions were performed, with 30 seconds of rest between sets and one minute between equipment. The total time was 15 minutes.

Aerobic exercises with the use of a lower limb cycle ergometer and exercise intensity based on the modified Borg scale ${ }^{26}$. The exercise was divided into three stages: warm-up (five minutes; 2-3Borg scale); conditioning (ten minutes; 4-7 Borg scale); and cool-down (five minutes; 0-2 Borg scale).

Electrical stimulation with Russian electric current associated with upper and lower limb resisted exercise. The Russian current parameters were mode-synchronous; frequency-50 Hz; ON and OFF time - six seconds each: rise and fall time - two seconds each; intensity - most tolerable by the patient, reaching the motor threshold. During the movement, hantelsets or ankle weights were used, with the load increasing by $1 \mathrm{~kg}$ every two weeks, beginning 
with $1 \mathrm{~kg}$, and ending with $4 \mathrm{~kg}$ in the last two weeks of the protocol. Three sets of 10 repetitions were performed, with two minutes of rest between sets. The femoral rectus, vastus medialis, and lateral muscles were stimulated and two electrode channels (lateral and medial compartment of the thigh) were used, both with a proximal electrode (at the motor point) and with a distal muscle (two centimeters of the upper pole of the patella). In addition, the brachial biceps muscle was stimulated with an electrode channel, maintaining one electrode at the proximal level, at the motor point, and another at the distal level (three centimeters above the articular line of the elbow). The total time was approximately 20 minutes.

\section{Measurements}

The same therapist performed all evaluations and interventions. The LAFAYETTE ${ }^{\circledR}$ portable digital dynamometer was used to assess muscle strength of the knee extensors. Dynamometry was performed according to the technique used by Schardong et al. ${ }^{27}$, and the peak value of the maximum isometric strength was recorded. The maneuver was repeated three times in both legs, and the maximum value was recorded.

The palmar grip strength was measured using a JAMAR ${ }^{\circledR}$ dynamometer. The participants remained seated and were asked to perform the greatest possible strength by squeezing the dynamometer, maintaining contraction for three to five seconds. The dynamometer was in position-2 for women and position-3 for men. The measurements were performed with the limb contralateral to the functioning fistula. The measurement was repeated three times, and the highest value was recorded ${ }^{28}$.

The respiratory muscle strength was evaluated through manovacuometry with an analogue manovacuometer (Instrumentation Industries $^{\circledR}$ ), connected to a nozzle, which measures pressures from 0 to $+120 \mathrm{cmH}_{2} \mathrm{O}$ for expiratory pressures and from 0 to $-120 \mathrm{cmH}_{2} \mathrm{O}$ for inspiratory pressures, according to the guidelines of the American Thoracic Society ${ }^{29}$. Three acceptable maneuvers were performed and the mean value was recorded. Previous data was analyzed using the reference equation proposed to Brazilian population $^{30}$.

Spirometry tests were used to evaluate lung function through a Datospir Micro digital portable spirometer-Model C (SIBELMED $\left.{ }^{\circledR}\right)$. Forced Vital Capacity (FVC) and Forced Expiratory Volume (FEV1) variables were analyzed using a technique in compliance with the guidelines of the American Thoracic Society ${ }^{31}$. Spirometric data was analyzed using values predicted by Pereira et $\mathrm{al}^{32}$.

The functional capacity was analyzed from the six-minute walk test (6MWT), which is a submaximal test of functional capacity, following the recommendations of the American Thoracic Society $^{33}$. The maximum distance covered during the $6 \mathrm{MWT}$ was recorded. The walk distance was compared to Britto et al. ${ }^{34}$ reference equations.

\section{Data analysis}

The sample calculation was not performed because the sample was of the intentional type due to maximization of the participants.
The data were submitted to the Shapiro-Wilk normality test, which revealed a normal distribution of the data. Next, the variables that obtained $p>0.05$ were analyzed by the Student's t-test for paired samples. The variables that obtained $\mathrm{p}<0.05$ were analyzed by the Wilcoxon's non-parametric test.

The significance level was set at 5\% for all tests. As for the numerical variables, measures of central tendency and dispersion were taken (standard deviation and mean). The categorical variables were evaluated in absolute relative percentage.

All variables were complemented with measurements of effect size (Cohen's d: small, $\mathrm{d}=0$ to 0.2 ; medium, $\mathrm{d}=0.2$ to 0.5 ; large, $\mathrm{d}=0.5$ to 0.8 ; and very large $>0.8$ ), and the power of the test was calculated using statistical software. All tests were performed using SPSS Statistics 22.0 software (IBM Corporation, New York, USA).

\section{Results}

\section{Flow of participants through the study}

Recruitment occurred between March and September 2017. The flowchart of selection of study participants is described in Figure 2. A total of 28 participants were screened for eligibility and 17 were excluded.

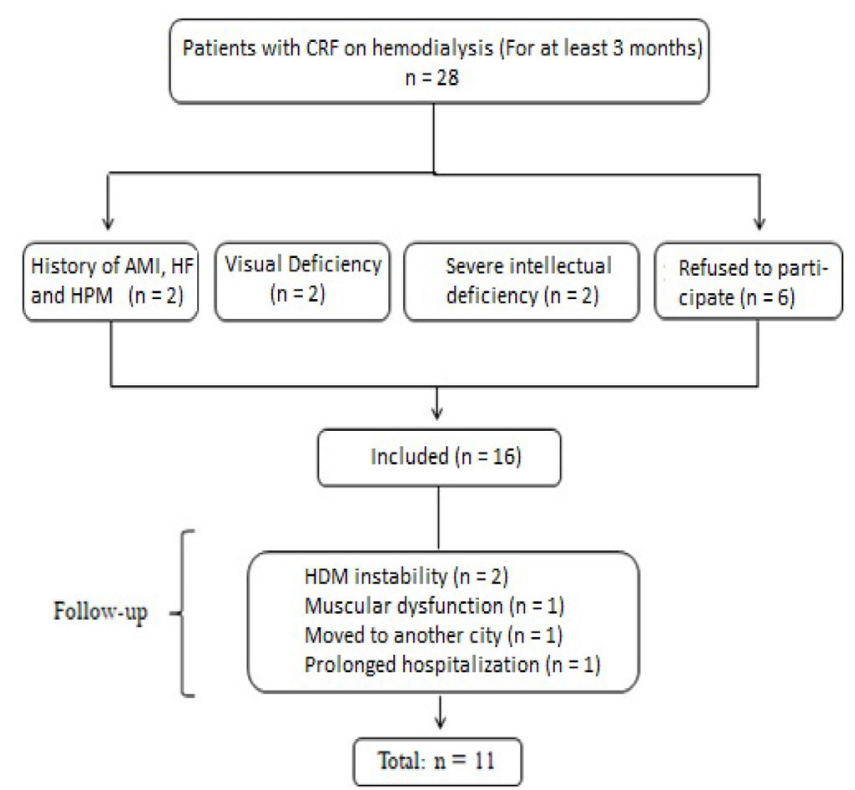

Figure 2 - Flowchart of selection of study participants; CRF: Chronic Renal Failure; AMI: Acute Myocardial Infarction; HF: Heart Failure; HPM: heart pacemaker; HDM: hemodynamic.

The sample was composed of eleven participants $(49.2 \pm$ 8.6 years). The demographic characteristics of the participants are summarized in Table 2, and the sample was characterized according to HRV data (Table 1). We can observe that in the linear analysis, as well as in the non-linear analysis, the participants already presented low HRV. 
TABLE 2 - Characteristics of the participants with Chronic Renal Failure on hemodialysis.

\begin{tabular}{cc}
\hline Variables & Participants $(\mathrm{n}=11)$ \\
\hline Age, mean (SD), years & $49(8.6)$ \\
Sex (M/F), n (\%) & $63.6 \% / 36.4 \%$ \\
Time of hemodialysis treatment \\
(months) \\
Weight, mean (SD), kg \\
Height, mean (SD), m \\
Comorbidities, n (\%) \\
\end{tabular}

$\mathrm{Kg}=$ Kilograms; $\mathrm{m}$ = meters. SAH: systemic arterial hypertension; DM: diabetes mellitus.
Results related to lung function, respiratory muscle strength, peripheral strength (quadriceps strength), palmar grip strength, and physical conditioning, before and after the proposed protocol, are summarized in Table 3.

According to table 3, it is possible to see that the group studied showed decreased lung function, respiratory muscle strength, and functional capacity, when compared to the Brazilians' average. The mean of all these variables was higher after treatment, except for FVC, which showed similar values as in the beginning of the protocol. The variables of maximal expiratory pressure (MEP) (Cohen's $d=0.59,95 \%$ CI 100.3 to 139.7), palmar grip strength (Cohen's $d=0.52,95 \%$ CI 26.32 to 42.68 ), left quadriceps strength (Cohen's $d=0.77,95 \% \mathrm{CI}$ 44.3 to 56.72 ), and distance walked in the 6MWT'(Cohen's $\mathrm{d}=0.83,95 \%$ CI 398.7 to 526.39 ) demonstrated statistically significant increases as well as large to very large effect sizes.

For the values of FEV1, FVC, MIP and right quadriceps strength, no statistically significant differences were found, although the statistical power of these variables was considered between medium and large.

TABLE 3 - Pre- and post-intervention variables analyzed in individuals with Chronic Renal Insufficiency on hemodialysis.

\begin{tabular}{|c|c|c|c|c|c|c|c|}
\hline & \multirow{2}{*}{ Variable } & \multirow{2}{*}{ Expected values } & \multicolumn{2}{|c|}{ Mean (SD) } & \multicolumn{2}{|c|}{ Statistical Analysis } & \multirow{2}{*}{ p-value } \\
\hline & & & BEFORE & AFTER & EFFECT SIZE & TEST POWER & \\
\hline & FEV1 & $3,43(0,57)$ & $3,06(0,86)$ & $3,19(0,97)$ & 0,14 & 0.57 & 0,472 \\
\hline \multicolumn{8}{|l|}{ Spirometry (L/sec) } \\
\hline & FVC & $4,26(0,74)$ & $4,32(1,11)$ & $4,32(1,27)$ & 0,01 & 0.97 & 0,979 \\
\hline \multirow{2}{*}{$\begin{array}{l}\text { Manovacuometry } \\
\qquad(\mathrm{cmH} 2 \mathrm{O})\end{array}$} & MIP & - 104,81 (14,45) & $-90,45(38,23)$ & $-94,54(27,33)$ & 0,12 & 0,69 & 0,663 \\
\hline & MEP & $110,74(19,30)$ & $102,72(29,44)$ & $120(29,32)$ & 0,59 & 0,53 & $0,012^{*}$ \\
\hline $\begin{array}{l}\text { Palmar grip dyna- } \\
\text { mome-try (kgF) }\end{array}$ & $\begin{array}{l}\text { Overall mus- } \\
\text { cle strength }\end{array}$ & ----- & $31,09(9,12)$ & $36(9,93)$ & 0,52 & 0,60 & $0,001 *$ \\
\hline $\begin{array}{l}\text { Dynamome-try of } \\
\text { right quadriceps } \\
(\mathrm{kgF})\end{array}$ & $\begin{array}{l}\text { Right quadri- } \\
\text { ceps strength }\end{array}$ & ------ & $45,4(11,69)$ & $50,57(20,53)$ & 0,32 & 0,55 & 0,395 \\
\hline $\begin{array}{c}\text { Dynamome-try } \\
\text { of left quadriceps } \\
(\mathrm{kgF})\end{array}$ & $\begin{array}{l}\text { Left quadri- } \\
\text { ceps strength }\end{array}$ & ------ & $44,64(9,25)$ & $53,62(14,33)$ & 0,77 & 0,52 & $0,025^{*}$ \\
\hline $\begin{array}{l}\text { Six-minute walk } \\
\text { test }(\mathrm{m})\end{array}$ & $\begin{array}{l}\text { Distance } \\
\text { walked in } \\
6 \mathrm{MWT}\end{array}$ & $588(31,04)$ & $385,09(91,57)$ & $462,54(95,03)$ & 0,83 & 0,39 & $0,009^{*}$ \\
\hline
\end{tabular}

L/sec: liters per second, cmH2O: centimeters of water; KgF: kilogram force; m: meters; FEV1: forced expiratory volume in the first second; FVC: Forced Vital Capacity; MIP: Maximum Inspiratory Pressure; MEP: Maximum Expiratory Pressure; 6MWT: six-minute walk test. *: statistically significant difference $(\mathrm{p} \leq 0.05)$. Paired T-test (parametric samples) and Wilcoxon's test (non-parametric sample). Cohen's d Effect Size. 


\section{Discussion}

The major findings occurred in the expiratory, peripheral and overall muscle strength as well as in the functional capacity of individuals with CRF on HD.

The participants with CRF on HD showed low HRV, which is the main feature related to increased risk of cardiovascular events and responsible for the growing number of hospitalizations in this population with $\mathrm{CRF}^{35}$. Therefore, it is important to evaluate this parameter even as a prognostic factor as well as to promote measures to improve autonomic modulation, including moderate-intensity physical exercise in the daily life of these individuals ${ }^{36}$.

Our findings indicate that the participants already showed significantly reduced HRV before the protocol (RMSSD: $14.49 \pm 13.14 \mathrm{~ms}$; SDNN: $21.04 \pm 12.89 \mathrm{~ms}$; LF: $184.11 \pm 283.02$ $\mathrm{ms}^{2}$; HF: $50.9 \pm 96.86 \mathrm{~ms}^{2}$ ), when compared to the healthy population ${ }^{37}$ (RMSSD: $27 \pm 12 \mathrm{~ms}$; SDNN: $141 \pm 9 \mathrm{~ms}$; LF: $1170 \pm 416$ $\mathrm{ms}^{2}$; HF: $975 \pm 203 \mathrm{~ms}^{2}$ ) and hypertensive patients in the same age group ${ }^{38}$, that is, the participants of this study already presented a marked dysfunction in the autonomic modulation of $\mathrm{HR}$, highlighting the importance of HRV in the prognosis of these individuals.

In addition to the involvement of the autonomic nervous system, one of the organs most affected by CRF is the lungs. Patients with CRF terminal stage have chronic pulmonary edema, which can cause pulmonary congestion, impairing the diffusion capacity of the lungs, due to the excess of accumulated fluid, causing gas exchange disturbances and, consequently, worsening pulmonary function ${ }^{4}$. The spirometric values did not present a significant increase. This can be explained by the fact that the HD procedure assists in the removal of the accumulated fluid. Therefore, there was an improvement of the spirometric variables after this procedure ${ }^{3}$, and the proposed protocol and the spirometric evaluation were performed at the beginning of the HD session, when there was still no significant loss of excess fluid.

Individuals with $\mathrm{CRF}$ on $\mathrm{HD}$ showed decreased spirometric, respiratory muscle strength, and 6MWT performance results before the beginning of the proposed exercise program. Even though these values increased after the protocol, most of these variables were still lower than the expected to the Brazilian population. The exception was the MEP, which had higher than expected results.

Also in this context, the physiotherapy intervention also provided an increase in the values of respiratory muscle strength, mainly in MEP. Similar results were found by Figueiredo et al. ${ }^{39}$, who reported a significant increase in MIP and MEP after an inspiratory muscle training protocol with individuals with CRF on HD, with only six weeks of treatment. In addition, other benefits have been demonstrated with the inclusion of respiratory rehabilitation in these individuals, such as a significant increase in lung function, respiratory muscle strength, functional capacity and improved quality of life ${ }^{40}$.

Although no load was applied to the expiratory muscles, there was an increase in MEP. This can be explained by the fact that, with the training, the inspiratory muscles become stronger and are able to move the chest to a more expanded position in preparation for the maneuver of MEP measurement. This more expanded position means greater elastic recoil of the lungs and chest wall, which may have led to the increase in $\mathrm{MEP}^{40}$.

Loss of muscle mass in CRF is a significant and common feature that affects the activities of daily living and is associated with reduced quality of life and increased mortality rate ${ }^{41}$. In addition to the benefits in the respiratory system, the proposed intervention protocol in this study was effective in gaining overall muscle strength.

Regular physical activity has beneficial effects on the cardiometabolic, neuromuscular and cognitive function in all stages of CRF. Therefore, changes in lifestyle should be an integral part of the treatment of renal diseases ${ }^{19}$. Several studies have proposed physical exercise during $\mathrm{HD}^{42-44}$, but there is still no consensus as to which protocol is most beneficial for these patients. The present study proposed the implementation of a mixed exercise protocol, given that generalized muscle weakness is observed in this population.

In addition to the combination of exercises, the major differential aspect of the physiotherapy intervention protocol was the use of the Russian stimulation associated with resisted exercises. Schardong et al. ${ }^{27}$ performed a similar electrostimulation protocol to the present study, with the same intervention time and with a reduced sample size (control group $n=10$ and intervention group $\mathrm{n}=11$ ), although without an association with resisted exercises. They also reported that neuromuscular electrostimulation promoted an increase in lower limb muscle strength and had a protective effect on muscle hypotrophy, but with no improvement in the functional capacity of these individuals.

The resisted exercise associated with the Russian electric current might have influenced the improved results found in the lower-limb muscle strenght. In the Chiguira et al. ${ }^{44}$ study, even though individuals perfomed several aerobic and resistance exercises, such as cycle ergometer and Thera-band with progressive loads, during maintenance dialysis, there was significant improvement in the lower-limb muscle strength values.

In the present study, improved functional capacity was evidenced by the increase in the distance covered in the 6MWT, and this can be explained by the gain of muscular strength promoted by the electrical stimulation associated with resisted exercises, aerobic exercises, as well as the improvement of the respiratory conditions. Similar results were found by Pellizzaro, Thomé and Veroneze ${ }^{45}$, who submitted HD patients to muscle training for 10 weeks. The authors observed a significant increase in functional capacity, suggesting that impairment of functional capacity in CRF patients may be attenuated by gain in muscle strength.

Patients diagnosed with CRF on HD have reduced functional capacity $^{46}$, especially due to the more sedentary lifestyle that is imposed by the routine of HD. The patients perform this procedure during about four hours, three times a week, and very often, other uncomfortable symptoms are associated with the treatment, making the patients feel unwell.

Individuals with CRF during HD should be encouraged to increase their fitness level, which may consequently improve their prognosis ${ }^{47}$. In this context, the proposed intervention protocol 
proved to be an applicable, effective and safe alternative, since no adverse events were reported during the research.

However, some limitations could be observed. This was a quasi-experimental clinical study with a small sample size, similar to other studies ${ }^{42,44,46}$. The small number of participants may be explained by the low adherence of physical exercise during HD. Most patients were used to monotonous HD sessions, inactivity during HD and sedentary behavior in general, demonstrating resistance to lifestyle changes. In addition, it could be observed that these participants had emotional alterations, which became worse in the subsequent weeks. This may have influenced the results of the research. Future studies should be performed using a randomized controlled trial to confirm our results.

\section{Conclusion}

It can be concluded that the proposed protocol is effective in increasing knee extensor muscle strength, palmar grip strength, expiratory muscle strength and functional capacity of individuals with CRF on HD.

\section{References}

1. Junior JER. Doença Renal Crônica: Definição, Epidemiologia e Classificação. J Bras Nefrol. 2004; 26(3):1-3.

2. Riella MC. Princípios de nefrologia e distúrbios hidroeletrolíticos. 2.ed. Rio de Janeiro: Guanabara Koogan; 1996.

3. Bianchi PD, Barreto SSM, Thomés FS, Klein AB. Repercussão da Hemodiálise na Função Pulmonar de Pacientes com Doença Renal Crônica Terminal. J Bras Nefrol. 2009; 31(1): 25-31.

4. Guyton AC, Hall JE. Tratado de Fisiologia Médica. Elsevier. 2006, 11ed, pg: 406-14.

5. Engel, C. Nefrologia. MedyKlin Editora. 2014, vol.5, pg. 27-42.

6. Cury JL, Brunetto AF, Aydos RD. Efeitos negativos da insuficiência renal crônica sobre a função pulmonar e a capacidade funcional. Rev. bras. fisioter. 2010; 14(2): 91-98.

7. Jatobá JPC, Amaro WF, Andrade APA, Cardoso FPF, Monteiro AMH, Oliveira MAM. Avaliação da Função Pulmonar, Força Muscular Respiratória e Teste de Caminhada de Seis Minutos em Pacientes Portadores de Doença Renal Crônica em Hemodiálise. J Bras Nefrol. 2008; 30(4): 280-7.

8. Mukai H, Ming P, Lindholm B, Heimbürger O, Barany P, Stenvinkel P, et al. Lung Dysfunction and Mortality in Patients with Chronic Kidney Disease. Kidney Blood Press Res. 2018; 43(2): 522-535.https://doi.org/10.1159/000488699.

9. Souza VA, Oliveira D, Mansur HN, Fernandes NM, Bastos MG. Sarcopenia na Doença Renal Crônica. J Bras Nefrol. 2015; 37(1): 98-105.

10. Fahal IH. Uraemic sarcopenia: aetiology and implications. Nephrol Dial Transplant. 2014; 29: 1655-1665.https://doi. org/10.1093/ndt/gft070

11. De Jager DJ, Grootendorst DC, Jager KJ, van Dijk PC, Tomas LM, Ansell D, et al. Cardiovascular and Noncardiovascular Mortality Among Patients Starting Dialysis. JAMA. 2009; 302(16): 1782-9. https://doi.org/10.1001/jama.2009.1488
12. Paraskevas KI, Kotsikoris I, Koupidis SA, Tzovaras AA, Mikhailidis DP. Cardiovascular events in chronic dialysis patients: emphasizing the importance of vascular disease prevention. Int Urol Nephrol. 2010; 42: 999-1006.https://doi. org/10.1007/s11255-010-9795-7

13. Oliveira CA, Brito Junior HL, Bastos MG, de Oliveira FG, Casali TG, Bignoto TC, et al. Depressed cardiac autonomic modulation in patients with chronic kidney disease. J Bras Nefrol. 2014; 36(2): 155-62.https://doi. org/10.5935/0101-2800.20140025

14. Rubinger D, Backenroth R, Sapoznikov D. Sympathetic nervous system function and dysfunction in chronic hemodialysis patients. Semin Dial. 2013; 26: 333-43. https://doi. org/10.1111/sdi.12093

15. Ranpuria R, Hall M, Chan CT, Unruh M. Heart rate variability (HRV) in kidney failure: measurement and consequences of reduced HRV. Nephrol Dial Transplant. 2008; 23: 444-9. https://doi.org/10.1093/ndt/gfm634

16. Liu M, Takahashi H, Morita Y, Maruyama S, Mizuno M, Yuzawa $Y$, et al. Non-dipping is a potent predictor of cardiovascular mortality and is associated with autonomic dysfunction in haemodialysis patients. Nephrol Dial Transplant. 2003; 18 : 563-569.https://doi.org/10.1093/ndt/18.3.563

17. Stein PK, Barzilay JI, Chaves PH, Traber J, Domitrovich PP, Heckbert SR,et al. Higher levels of inflammation factors and greater insulin resistance are independently associated with higher heart rate and lower heart rate variability in normoglycemic older individuals: The Cardiovascular Health Study. J Am Geriatr Soc. 2008; 56: 315-321.https://doi. org/10.1111/j.1532-5415.2007.01564.x

18. Oliveira ACF, Vieira DSR, Bündchen DC. Level of Physical Activity and functional capacity of patients with pre-dialytic chronic kidney disease and in hemodialysis. Fisioter Pesqui. 2018;25(3):323-329. https://doi. org/10.1590/1809-2950/18003625032018.

19. Zelle DM, Klaassen G, van Adrichem E, Bakker SJ, Corpeleijn E, Navis G. Physical inactivity: a risk factor and target for intervention in renal care. Nat Rev Nephrol. 2017; 13(3): 152168.https://doi.org/10.1038/nrneph.2016.187

20. Wilkinson TJ, Shur NF, Smith AC. "Exercise as medicine" in chronic kidney disease. Scand J Med Sci Sports. 2016; 26(8): 985-988.https://doi.org/10.1111/sms.12714

21. Kang SH, Do JY, Jeong HY, Lee SY, Kim JC. The Clinical Significance of Physical Activity in Maintenance Dialysis Patients. Kidney Blood Press Res. 2017; 42(3): 575-586. https://doi.org/10.1159/000480674

22. Roxo RS, Xavier VB, Miorn LA, Magalhães AO, Sens YAS, Alves VLS. Impacto da estimulação elétrica neuromuscular na capacidade funcional de pacientes com doença renal crônica submetidos à hemodiálise. J Bras Nefrol. 2016;38(3):344-350. https://doi.org/10.5935/0101-2800.20160052

23. Quintana DS, Heathers JA, Kemp AH. On the validity of using the Polar RS800 heart rate monitor for heart rate variability research. Eur J Appl Physiol. 2012; 112(12): 4179-80. https:// doi.org/10.1007/s00421-012-2453-2

24. Dos Santos L, Pillat V, de Godoy MF, Barbosa CL, Barroso J, Macau E. T-RR Filter: Ferramenta computacional gráfica no 
uso do filtro adaptativo para análise da variabilidade da frequência cardíaca. Proc. Series. Braz. Soc. Comp. Appl. Math. 2016; 4(1): 1133-1139.

25. Niskanen JP, Tarvainen MP, Ranta-Aho PO, Karjalainen PA. Software for advanced HRV analisys. Comput. Methods. Programs. Biomed. 2004; 76(1): 73-81.https://doi. org/10.1016/j.cmpb.2004.03.004

26. Foster C, Florhaug JA, Franklin J, Gottschall L, Hrovatin LA, Parker S, et al. A new approach to monitoring exercise training. J Strength Cond Res. 2001; 15(1): 109-115.

27. Schardong J, Dipp T, Bozzeto CB, da Silva MG, Baldissera GL, Ribeiro RC, et al. Effects of Intradialytic Neuromuscular Electrical Stimulation on Strength and Muscle Architecture in Patients with Chronic Kidney Failure: Randomized Clinical Trial. Artif Organs. 2017; 41(11): 1049-1058.https://doi. org/10.1111/aor.12886

28. Sallinen J, Stenholm S, Rantanen T, Heliövaara M, Sainio P, Koskinen S. Hand- Grip Strength Cut-Points to Screen Older Persons at Risk for Mobility Limitation. J Am Geriatr Soc. 2010; 58(9): 1721-1726.https://doi. org/10.1111/j.1532-5415.2010.03035.x

29. American Thoracic Society/European Respiratory Society. ATS/ ERS Statement on respiratory muscle testing. Am J Respir Crit Care Med. 2002; 166(4): 518-624. https://doi.org/10.1164/rccm.166.4.518

30. Pessoa IMBS, Neto MH, Montemezzo D, Silva LAM, Andrade $\mathrm{AD}$, Parreira VF. Predictive equations for respiratory muscle strength according to international and Brazilian guidelines. Braz J Phys Ther. 2014 Sept-Oct; 18(5):410-418. https://doi.org/10.1590/ bjpt-rbf.2014.0044

31. American Thoracic Society. Standardization of spirometry, 1994 update. Am J Respir Crit Care Med. 1995; 152: 1107-1136.https:// doi.org/10.1164/ajrccm.152.3.7663792

32. Pereira CAC, Sato T, Rodrigues SC. Novos valores de referência para espirometria forçada em brasileiros adultos de raça branca. J Bras Pneumol. 2007;33(4):397-406

33. ATS Committee on Proficiency Standards for Clinical Pulmonary Function Laboratories. ATS statement: guidelines for the six-minute walk test. Am J Respir Crit Care Med. 2002; 166(1): 111-7.https:// doi.org/10.1164/ajrccm.166.1.at1102

34. Britto RR, Probst VS, Andrade AFD, Samora GAR, Hernandes NA, Marinho PEM, et al. Reference equations for the six-minute walk distance based on a Brazilian multicenter study. Braz J Phys Ther. 2013;17(6):556-63. https://doi.org/10.1590/ S1413-35552012005000122

35. Huang JC, Kuo IC, Tsai YC, Lee JJ, Lim LM, Chen SC, et al. Heart Rate Variability Predicts Major Adverse Cardiovascular Events and Hospitalization in Maintenance Hemodialysis Patients. Kidney Blood Press Res. 2017; 42: 76-88. https://doi.org/10.1159/000469716

36. Barcellos FC, Santos IS, Umpierre D, Bohlke M, Hallal PC. Effects of exercise in the whole spectrum of chronic kidney disease: a systematic review. Clin Kidney J. 2015; 8(6): 753-765. https://doi. org/10.1093/ckj/sfv099

37. de Medeiros AIC, Fuzari HKB, Rattesa C, Brandão DC, de Melo Marinho PÉ. Inspiratory muscle training improves respiratory muscle strength, functional capacity and quality of life in patients with chronic kidney disease: a systematic review. J Physiother. 2017; 63(2): 76-83. https://doi.org/10.1016/j.jphys.2017.02.016

38. Chen CT, Lin SH, Chen JS, Hsu YJ. Muscle wasting in hemodialysis patients: new therapeutic strategies for resolving an old problem. ScientificWorldJournal. 2013; 2013: 643954.

39. Groussard C, Rouchon-Isnard M, Coutard C, Romain F, Malardé L, Lemoine-Morel S, et al. Beneficial effects of an intradialytic cycling training program in patients with end-stage kidney disease. Appl Physiol Nutr Metab. 2015; 40(6): 550-556.https://doi. org/10.1139/apnm-2014-0357

40. Bennett PN, Fraser S, Barnard R, Haines T, Ockerby C, Street $\mathrm{M}$, et al. Effects of an intradialytic resistance training programme on physical function: a prospective stepped-wedge randomized controlled trial. Nephrol Dial Transplant. 2016; 31(8): 1302-1309.https://doi.org/10.1093/ndt/gfv416

41. Chigira Y, Oda T, Izumi M, Yoshimura T. Effects of exercise therapy during dialysis for elderly patients undergoing maintenance dialysis. J Phys Ther Sci. 2017; 29(1): 20-23. https:// doi.org/10.1589/jpts.29.20

42. Pellizzaro CO, Thomé FS, Veronese FV. Effect of peripheral and respiratory muscle training on the functional capacity of hemodialysis patients. Ren Fail. 2013; 35(2): 189-97. https:// doi.org/10.3109/0886022X.2012.745727

43. Cunha MS, Andrade V, Guedes CAV, Meneghetti CHZ, Aguiar AP, Cardoso AL. Assessment of functional capacity and quality of life in chronic renal patients under hemodialysis treatment. Fisioter Pesq. 2009; 16(2): 155-160.https://doi.org/10.1590/ S1809-29502009000200011

44. Kang SH, Do JY, Jeong HY, Lee SY, Kim JC. The Clinical Significance of Physical Activity in Maintenance Dialysis Patients. Kidney Blood Press Res. 2017; 42(3): 575-586. https://doi.org/10.1159/000480674

\section{Corresponding author}

Mayara Simões

Rua Vigário Carlos, 100, Centro de Pesquisas Professor Aluízio Rosa Prata, sala 319, 38025-350, Uberaba, Minas Gerais, Brazil;

E-mail: mayara_simoes_13@hotmail.com

Editor: Romulo A Fernandes. UNESP/Presidente Prudente, SP, Brazil

Manuscript received on January 4, 2020

Manuscript accepted on May 12, 2020

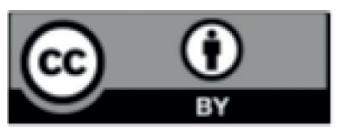

Motriz. The Journal of Physical Education. UNESP. Rio Claro, SP, Brazil - eISSN: 1980-6574 - under a license Creative Commons - Version 4.0 